\title{
O feminismo espinosano de Marilena Chaui: Espinosa contra as Amazonas ou a hipótese contrária
}

Henrique Piccinato Xavier ${ }^{1}$

Resumo: A partir de um dos primeiros textos publicados por Marilena Chaui, o "Terceira margem. Notas para um rodapé selvagem" de 1976, que inaugura a sua reflexão acerca do estatuto político das mulheres e, ao mesmo tempo, amadurece suas primeiras ideias acerca do que viria constituir o Nervura do real (sua principal obra sobre Espinosa), o nosso ensaio se pergunta acerca da possibilidade de um feminismo espinosano operando na obra de Chaui. Para tanto, procuramos dar conta de como o referido texto de 1976 aborda a aparente hipótese da rejeição da participação das mulheres na democracia no Tratado político de 1677 de Espinosa, sendo esta rejeição um problema enfrentado pelas principais feministas contemporâneas que recorrem à filosofia de Espinosa para fundamentar suas ideias e lutas. Levando em conta esta última consideração e o fato de que no Brasil ainda sejam raras as aproximações entre feminismo e Espinosa (algo diferente do que acontece internacionalmente), o nosso ensaio apresenta um apêndice contendo o mapeamento das principais obras, autoras e linhas do que contemporaneamente vem a ser chamado de feminismo espinosano.

Palavra-chave: Marilena Chaui - Bento de Espinosa - Feminismo - Democracia - Tratado político

\section{The Spinozist feminism of Marilena Chaui: Espinosa against the Amazons or the counterhypothesis}

\begin{abstract}
Considering one of the first texts published by Marilena Chaui, the "Terceira margem. Notas para um rodapé selvagem" from 1976, which inaugurates her reflection on the political status of women and, at the same time, develops her first ideas that would become Nervura do real (her main work on Spinoza), our essay inquires about the possibility of a Spinozist feminism operating in Chaui's works. To accomplish this, we aim to give an account of how the aforementioned text from 1976 addresses the apparent hypothesis of the rejection of women's participation in a democracy in Spinoza's Political Treatise of 1677 , this rejection being a problem faced by the main contemporary feminists who call upon Spinoza's philosophy to base their ideas and struggles. Taking this last consideration into account and the fact that in Brazil the relations between feminism and Spinoza are still rare (something different from what happens internationally), our essay presents an appendix containing the mapping of the main works, authors, and approaches considered today as Spinozist feminism.
\end{abstract}

Keywords: Marilena Chaui - Baruch Spinoza - Feminism - Democracy - Political Treatise

${ }^{1}$ Doutor em Filosofia pelo Departamento de Filosofia da FFLCH-USP. E-mail: henrique.xavier0@gmail.com. 
Comecemos com o antigo relato de uma sociedade que além de matriarcal, veio a ser formada apenas por mulheres, refiro-me às Amazonas, antigas guerreiras retratadas em batalhas contra guerreiros gregos. Mais que lutar contra os homens, elas invadiam e tomavam aquilo que por muitos foi chamado do berço da cultura e da filosofia ocidental. Mulheres invasoras do espaço dos heroicos homens gregos, mulheres invasoras do berço da filosofia ocidental.

Nós nos referimos às Amazonas e a uma sociedade composta apenas por mulheres, pois tais guerreiras gregas são centrais no interior de um problema abordado por Marilena Chaui acerca da hipótese da não participação das mulheres na democracia no Tratado político de 1677 de Bento de Espinosa, autor de suma importância na trajetória da filósofa. A análise deste problema encontra-se em um dos primeiros textos por ela publicado, o "Terceira margem. Notas para um rodapé selvagem" ${ }^{2}$ de 1976, sendo o seu segundo texto publicado acerca da filosofia de Espinosa e, simultaneamente, a sua primeira publicação a tratar de questões de gênero ${ }^{3}$.

Embora um enfoque ainda muito pouco estudado no Brasil, há diversas feministas que contemporaneamente recorrem à obra de Espinosa para fundamentar suas lutas e filosofias. Espinosa se faz presente em diversas correntes de feminismo, do materialista ao queer, passando pelo anarco, pós-humano, dentre outras linhas, sendo que muitas das autoras que recorrem ao autor não são apenas filósofas, mas referências em suas linhas de trabalho com gênero, como, por exemplo, Judith Butler, Moira Gatens, Rosi Braidotti dentre outras. Existindo, contemporaneamente, sobretudo, no âmbito internacional, um amplo debate acerca do que podemos chamar de feminismo espinosano. É curioso ver como as primeiras ideias de Chaui sobre Espinosa, lá em 1976, já estavam vinculadas a uma reflexão de gênero. O que nos leva à pergunta: se as ideias de violência, opressão e servidão e as formas de combate a elas desenvolvidas por Espinosa são claramente um dos importantes fundamentos do pensamento político de Chaui, estaríamos corretos ao pensar que as reflexões da autora que tratam de violência de gênero, também, estariam operando a partir da filosofia de Espinosa? Existiria um feminismo espinosano de Marilena Chaui?

Vejamos como este grego, espinosano e feminista problema encarado por Chaui lá em 1976, com seus quarenta e quatro anos, pode interagir, antecipar, soar datado ou trazer uma contribuição para o atual debate sobre gênero e feminismo e, mais precisamente, para o debate acerca do feminismo espinosano. Para auxiliar este fim, o nosso ensaio traz o apêndice "Por um mapeamento do Feminismo Espinosano" que procura apresentar as principais autoras, livros e pesquisas que fazem parte desta corrente contemporânea de feminismo.

Além disto, incitando-nos a reler as Amazonas de Espinosa e a nos perguntar acerca da especificidade do feminismo de Chaui vem ser a iminente republicação do ensaio “Terceira margem” em um extenso livro que trará o conjunto das reflexões da filósofa sobre

${ }^{2}$ CHAUI, "Terceira margem. Notas para um rodapé selvagem”, p. 54-58.

3 A palavra gênero não é empregada no ensaio, uma vez que o uso contemporâneo do termo se torna mais corrente apenas a partir da década de noventa pelo impacto de Problemas de gênero (1990) de Judith Butler, contudo procuraremos mostrar como algumas questões centrais deste debate já são trabalhadas por Chaui em 1976. 
gênero, feminismo e sexualidade, livro que será o oitavo volume da Coleção Escritos de Marilena Chanit.

Dentre as numerosas autoras feministas contemporâneas que, internacionalmente, recorrem à filosofia de Espinosa para fundamentar suas ideias e engajamentos (ver o apêndice "Por um mapeamento do Feminismo Espinosano"), praticamente a todas elas sempre cabe a ressalva ao último parágrafo do Tratado político de Espinosa. Elas precisam dizer quase em uníssono que, a despeito desta curta, inacabada e terrível passagem, a obra do filósofo holandês seiscentista é uma aliada importante para o desenvolvimento da luta feminista, alegando que a passagem seja uma estranha exceção que não condiz com o que é sistematicamente proposto pela filosofia de Espinosa. Não apenas as feministas, mas também especialistas em sua obra apontam severas críticas ao último parágrafo do Tratado, tomemos apenas dois exemplos: o primeiro de Moira Gatens, possivelmente a mais influente e citada autora no que podemos chamar de "feminismo espinosano", em seu livro Imaginary Bodies: Ethics, Power and Corporeality, ela encara a passagem como uma "cicatriz que desfigura a filosofia de Espinosa". Já o renomado especialista na obra espinosana Alexandre Matheron, levando em conta o fato de que o Tratado não foi concluído devido ao falecimento prematuro de Espinosa, em seu ensaio "Femmes et serviteurs dans la démocratie spinoziste", ele chega à bizarra e inverossímil conclusão:

O incômodo sentido por Espinosa nas últimas linhas do Tratado, não vem do fato dele assumir preconceitos sem relação com os princípios [de sua filosofia], mas do fato de que, nesse preciso ponto, as consequências de seus princípios são cruéis... Talvez, em definitivo, são, de fato, o suficiente para fazê-lo cessar e disso morrer! ${ }^{6}$

No caso de Marilena Chaui ocorre algo muito diferente, pois ela enfrenta a fatídica passagem de Espinosa a partir de uma leitura cuidadosa da trama argumentativa do Tratado político, sendo capaz de demonstrar que a passagem apenas aparentemente opera contra as mulheres $^{7}$, pois, inversamente, quando bem interpretadas, tais palavras abrem um caminho,

\footnotetext{
${ }^{4}$ CHAUI, oitavo volume da Coleção Escritos de Marilena Chaui, no prelo, 2021. O livro está atualmente sendo organizado na Coleção Escritos de Marilena Chaui (coordenada por Homero Santiago, Erika Itokazu e André Rocha) e conterá uma ampla seleção de textos da filósofa, desde o mencionado "Terceira margem. Notas para um rodapé selvagem” de 1976; passando pelo livro Repressão sexual: essa nossa (des)conbecida de 1984; pelos longos ensaios "Participando do debate sobre mulher e violência" de 1985 e "Do silêncio à palavra" de 2006; por vários artigos "As mulheres e a pornografia", "As mulheres do Juqueri", "Romper tutelas", "A questão do aborto", "Seres morais, apenas", "Poesias implodem o ideal feminino", "O público, o privado e as mulheres", dentre outros; até alcançar as suas mais recentes publicações como o artigo "Orides Fontela: poesia e filosofia" de 2020; um arco de publicações que evidencia uma ampla e poliforme reflexão de Chaui que continua em pleno desenvolvimento.

${ }^{5}$ GATENS, Imaginary Bodies: Ethics, Power and Corporeality, p. 134-135.

${ }^{6}$ MATHERON, Femmes et serviteurs dans la démocratie spinoziste, p. 386.

${ }^{7}$ Localizamos uma segunda exceção no debate sobre o parágrafo final do Tratado político, apresentada mais de quatro décadas mais tarde, o ensaio Gobernar a las mujeres. La proposición XI, 4 del Tratado Político de Spinoza, o los problemas de la relación naturaleza e historia (2018) de Cecilia Abdo Ferez que a partir da desconstrução espinosana
} 
um tanto subversivo, na filosofia do século XVII, para pensar a participação das mulheres na democracia.

A resposta à hipótese de "Espinosa contra as Amazonas" é o primeiro passo para a construção do que poderá ser entendido como o feminismo espinosano de Chaui. No presente ensaio, nós nos contentaremos em interpretar este primeiro passo, embora conscientes de que para uma realização satisfatória de tal construção teríamos que precisar os contornos da ampla reflexão sobre feminismo, gênero e sexualidade elaborada por Chaui no decorrer de sua trajetória ${ }^{8}$ e, ao mesmo tempo, precisar no interior destes contornos a ação de operações espinosanas, ambas tarefas bastante extensas e complexas, mas que se tornarão mais viáveis com a publicação do mencionado livro sobre gênero na Coleção Escritos. Trata-se, contudo, de um primeiro e definitivo passo uma vez que, simultaneamente, inaugura a reflexão de Chaui acerca do estatuto político das mulheres e, ao mesmo tempo, amadurece suas primeiras ideias acerca do que viria constituir o Nervura do real, sua obra máxima sobre Espinosa, que então começava a tomar a forma de uma tese de livre-docência'.

Também, um primeiro e definitivo passo, pois cabe salientar que o "Terceira margem. Notas para um rodapé selvagem” de 1976 de Marilena Chaui é a publicação mais antiga do que contemporaneamente vem a ser chamado de feminismo espinosano, antecedendo, por mais de uma década, o "Spinoza y las mujeres" de 1989 de Maite Larrauri e, por quase duas décadas, o Part of Nature: Self-Knowledge in Spinoza's Ethics de 1994 de Genevieve Mary Lloyd, ambas obras precursoras desta corrente de feminismo.

É notável como as duas primeiras partes do “Terceira margem” apresentam uma forma embrionária de questões que serão amplamente retomadas e desenvolvidas nos vários anos de escrita dos dois volumes do Nervura do real e dos demais livros sobre Espinosa e, por outro, mais notável ainda é o fato de que a hipótese negativa acerca das mulheres que mobiliza a terceira parte do ensaio jamais foi retomada por Chaui. Cremos (pois nos parece bastante verossímil) que precisamente em relação ao problema das mulheres, Marilena precisava (consciente ou inconscientemente) se reaver com Espinosa para sentir-se livre para, de fato, poder começar a redigir a sua mais significativa obra, o Nervura do real. Assim, lá em 1976, acreditamos que ela procura resolver satisfatoriamente um problema de ordem tanto intelectual como afetiva: enfrentar a inelutável questão das mulheres no Tratado de Espinosa.

A terceira parte do "Terceira margem" é intitulada "Questão feminina; questão de estilo" (cabe salientar que Chaui em 1976 ainda empregava a palavra "feminino" sem a conotação pejorativa que mais tarde tornou-se hegemônica com o desenvolvimento do feminismo contemporâneo), nesta parte, ela aborda o último parágrafo do Tratado político onde se encontra a absurda hipótese, aparentemente espinosana, de que a natural fragilidade das mulheres as conduziria a uma incessante disputa pelo poder com os homens, o que, por sua vez, engendraria o natural desejo feminino de tirania e, por isso, o mais racional seria têlas excluídas da vida política em uma democracia.

\footnotetext{
do binarismo natureza e história, procura contra-argumentar a posição antifeminista do parágrafo, fazendo com que as ideias de Ferez se aproximem bastante das conclusões de Chaui.

${ }^{8}$ Começamos a traçar as primeiras linhas deste contorno em "Histórias da sexualidade à brasileira" (XAVIER, 2020), capítulo do livro Marilena Chaui: Pensamento, afetos e análise da obra, onde realizamos uma análise do Repressão sexual: essa nossa (des)conhecida (CHAUI, 1984) a partir de um debate com as obras de Freud, Foucault e Butler.

${ }^{9}$ A primeira nota de rodapé do "Terceira Margem" traz a seguinte informação: "Os trechos aqui apresentados são notas de rodapé de um livro em preparação: 'A Nervura do Real - Espinosa e a Questão da Liberdade”'.
} 
Reproduzamos o fatídico parágrafo com o intuito de que não apenas as leitoras, leitores e leitorxs acompanhem nossa interpretação, mas para que possam de antemão formar suas próprias conclusões acerca do tamanho do problema:

Talvez haja quem pergunte se é por natureza ou por instituição que as mulheres devem estar sob o poder dos homens. Com efeito, se for só por instituição que tal acontece, então nenhuma razão nos obriga a excluir as mulheres do governo. Porém, se consultarmos a própria experiência, veremos que isto deriva da sua fraqueza. Em parte nenhuma aconteceu, com efeito, os homens e as mulheres governarem juntos, mas em qualquer parte da terra onde se encontrem homens e mulheres vemos os homens reinarem e as mulheres serem governadas, vivendo assim ambos os sexos em concórdia. Pelo contrário, as amazonas, de quem se espalhou a fama de terem outrora reinado, não toleravam homens a morar no solo pátrio: amamentavam só as fêmeas e, se parissem machos, matavam-nos. Se as mulheres fossem por natureza iguais aos homens e sobressaíssem igualmente pela fortaleza de ânimo e pelo engenho, que são aquilo em que acima de tudo consiste a potência humana e, por conseguinte, o direito, sem dúvida que, entre tantas e tão diversas nações, se encontrariam algumas onde os dois sexos governassem em paridade e outras onde os homens fossem governados pelas mulheres e educados de modo a terem, pelo engenho, menos poder. Como isto não aconteceu em parte nenhuma, é totalmente lícito afirmar que as mulheres, por natureza, não têm o mesmo direito que os homens e estão-lhes necessariamente submetidas, de tal modo que não é possível acontecer que ambos os sexos governem de igual modo e, muito menos, que os homens sejam governados pelas mulheres. Se, além disso, considerarmos os afetos humanos, ou seja, que os homens a maioria das vezes amam as mulheres só pelo afeto libidinoso e apreciam o seu engenho e a sua sabedoria só na medida em que elas sobressaem pela beleza, suportam com muita dificuldade que aquelas a quem amam se interessem de algum modo por outros, e coisas do mesmo gênero, facilmente veremos que não é possível, sem prejuízo grave da paz, homens e mulheres governarem de igual modo. Mas, sobre isto, já chega. ${ }^{10}$

\section{II}

A terceira parte do ensaio intitulada "Questão feminina; questão de estilo" é bem concisa, apenas seis densos parágrafos para desenvolver uma cuidadosa resposta ao que parece ser um inelutável problema desenvolvido apenas em um único e muito denso parágrafo de Espinosa. Propomos uma nova série de parágrafos para desdobrar os seis de Chaui, procurando revelar neles uma subversiva, porém precisa, em sentido espinosano, interpretação da autora.

${ }^{10}$ ESPINOSA, Tratado politico, p. 139-140. 
Chaui leva em conta o fato de que o capítulo final do Tratado político, o de número $\mathrm{XI}$, que especificamente trata da democracia, foi interrompido em seu quarto parágrafo que especificamente trata das mulheres (há também uma curta linha no terceiro acerca delas). A continuidade do texto não chega à posteridade, pois Espinosa morre antes de terminar a redação e não foram deixadas notas e outras informações sobre o seu desenvolvimento. Apenas quatro curtos parágrafos para dar conta do que Espinosa defendia ser "o mais natural dos regimes políticos", pois vem a ser o único que satisfaz ao desejo de todo ser humano de governar e não ser governado. Comparativamente os capítulos VI e VII que tratam da monarquia possuem cerca de oitenta parágrafos, então, por certo, ainda haveria muito a ser escrito sobre a democracia e sobre o problema das mulheres no capítulo XI.

O primeiro movimento da análise de Chaui vem demonstrar como o estilo argumentativo nas principais obras de Espinosa opera com um procedimento que parte de hipóteses não espinosanas para cuidadosamente desmontá-las e desde dentro do movimento de desmontagem apresentar propriamente as ideias espinosanas. Trata-se, sobretudo, de um método de subversão interno de ideias, de preconceitos e do senso comum dominantes em sua época, ou seja, temos a elaboração de uma espécie de "contradiscurso".

Chaui demonstra como este método é uma constante que assume variações para se adequar a cada uma de suas obras, por exemplo: "nos Pensamentos Metafísicos, Espinosa critica indiretamente os medievais e Descartes, reescrevendo as teses que combate na forma de orações hipotéticas (se... então), retirando das hipóteses conclusões que as negam”. Ela demonstra variações do procedimento operando nos Princípios da filosofia cartesiana, nos escólios da Ética, no Tratado teológico-político e, no Tratado político. Neste último, ela mostra como Espinosa produz um percurso em que a hipótese da causa instituinte da monarquia tende a paradoxalmente ser abolida:

Com efeito, a causa da monarquia é o medo da guerra que leva a massa a dar um poder desmesurado àquele que possui algo de que ela se encontra desprovida - o bom manejo das armas - e que o converterá em rei, e posteriormente em tirano, à medida que sua figura empírica for sendo identificada com a soberania. Ora, entre os procedimentos propostos pelo filósofo para conservar a monarquia, está a criação de um exército popular permanente - isto significa que, armando o povo, Espinosa lhe dá aquilo que só o rei possuía e que era a fonte de sua dominação. A tese do povo armado para conservar o corpo político monárquico é pelo menos... estranha. ${ }^{11}$

Após uma breve análise do procedimento nas outras obras, Chaui chega a conclusão de que:

Esse procedimento é tão constante no filósofo que poderíamos quase tomálo como uma espécie de 'norma' de leitura: as orações hipotéticas apresentam teses que não são espinosanas, que são levadas à auto-destruição no decorrer da argumentação. ${ }^{12}$

${ }^{11}$ CHAUI, "Terceira margem. Notas para um rodapé selvagem", p. 57.

${ }^{12}$ CHAUI, "Terceira margem. Notas para um rodapé selvagem", p. 56. 
Chaui, então, faz a afirmação extremamente ousada de que o fatídico último parágrafo do Tratado político que se refere às mulheres vem a ser um dos exemplos mais claros e bem acabados deste procedimento estilístico.

Voltemos ao parágrafo de Espinosa, este começa com a indagação: “Talvez haja quem pergunte se é por natureza ou por instituição que as mulheres devem estar sob o poder dos homens". A resposta será por natureza, feita sob a alegação da fragilidade ${ }^{13}$ natural das mulheres, pois caso fosse por instituição (pelos costumes, leis, educação, ou seja, por aquilo que hoje denominamos de cultura e história) então não haveria uma razão necessária que nos obrigasse a excluir as mulheres do governo e existiria a possibilidade delas serem integradas na democracia.

Está formada a hipótese do problema: a natural fragilidade das mulheres seria responsável por sua exclusão na democracia. Veremos como Chaui lerá o resto do parágrafo, demonstrando como cada novo passo de Espinosa já está, de um modo sorrateiro e desde dentro, desconstruindo tal hipótese.

Chaui chama atenção ao fato de que Espinosa, ao falar na fragilidade feminina, logo mencione a força das guerreiras Amazonas, "um exemplo no qual tudo pode estar presente, menos a fragilidade". Porém, o exemplo fornecido assinala um poder tirânico exercido às custas do infanticídio, pois as Amazonas matam as crianças de sexo masculino. Chaui nota que este traço não é assinalado por acaso, pois há um contraponto masculino no próprio Tratado, o Império do Grande Turco:

Com efeito, o despotismo turco é marcado pela guerra fratricida, onde o déspota se vê obrigado a matar todos os machos de sua família e das famílias mais próximas, pois, dado o caráter pessoal de seu poder, qualquer homem que esteja próximo do tirano pode perfeitamente aspirar por seu lugar. ${ }^{14}$

Assim, o contraponto entre as Amazonas e o Grande Turco torna irrelevante se são mulheres ou homens que exercem o poder, pois o que interessa é a forma de seu exercício, o poder é exercido pela via do extermínio. Não havendo uma diferença essencial ou natural entre a tirania masculina e feminina.

A argumentação de Chaui vem mostrar como a equivocada compreensão da oposição entre tirania e liberdade e entre servidão e liberdade engendrará as naturalizações da soberania masculina e da fragilidade feminina. Ela nos lembra como:

no Tratado da Reforma, na Ética, e também no Político, o primeiro momento da compreensão da servidão é dado pela compreensão das relações intersubjetivas onde a liberdade é imaginada como poder que se exerce sobre outrem, de sorte que, em lugar de aparecer como oposta à escravidão, a imagem da liberdade nasce da posição do escravo. ${ }^{15}$

\footnotetext{
${ }^{13}$ Cabe salientar que a tradução de 2009 do Tratado político por Diogo Pires Aurélio emprega o termo "fraqueza", enquanto o ensaio de Chaui de 1976 "fragilidade". Isto produzirá uma oscilação nos termos em nosso texto.

${ }^{14}$ CHAUI, "Terceira margem. Notas para um rodapé selvagem”, p. 57.

${ }^{15}$ CHAUI, "Terceira margem. Notas para um rodapé selvagem”, p. 57.
} 
O tirano produz a ilusória imagem de liberdade enquanto poder de mando, ou seja, o poder de negar aos outros a sua condição de liberdade. O raciocínio de Espinosa produz uma inversão engenhosa: o tirano, por não conhecer o verdadeiro sentido da liberdade, não é livre, mas é um "escravo" por excelência. Ele jamais pode ser considerado como um indivíduo livre, muito pelo contrário, é uma afronta à liberdade. Os escravizados, sob o poder de outro homem, obviamente não são livres; e o tirano, o escravizador, é um terrível empecilho à liberdade.

Em direção oposta à falsa imagem da liberdade enquanto poder de mando, a liberdade espinosana irá depender justamente da condição de uma coletividade de pessoas reciprocamente livres. Exercer a liberdade é não ser impedido por outrem, e a única condição para que isto ocorra é a exigência do convívio com demais pessoas livres. Cito Chaui:

Com efeito, Espinosa declara que somente na Cidade os homens vivem uma vida propriamente humana, para além da aderência animal ao imediato; e define a democracia como poder absoluto exercido pela coletividade constituída por homens livres, pois a liberdade é não estar em poder de outrem, seja pelo ferro ou pelo fogo, seja pelo logro das promessas, seja, enfim, pelo medo das ameaças. ${ }^{16}$

O próximo passo de Espinosa nos leva a compreender que a fragilidade e submissão das mulheres não provém de uma condição natural, em sentido biológico, que definiria o seu ser, mas provém de uma ação masculina que conduz as mulheres a um ponto extremo de servidão, ou seja, de ausência extrema de liberdade. Cito Espinosa e Chaui:

Se, além disso, considerarmos os afetos humanos, ou seja, que os homens a maioria das vezes amam as mulheres só pelo afeto libidinoso e apreciam o seu engenho e a sua sabedoria só na medida em que elas sobressaem pela beleza, suportam com muita dificuldade que aquelas a quem amam se interessem de algum modo por outros (...). ${ }^{17}$

No caso analisado, é o olhar masculino que produz a servidão feminina. A mulher é vista exclusivamente como objeto de prazer, a tal ponto que suas qualidades intelectuais e morais (Espinosa não lhe recusa tais qualidades) permanecem soterradas, só vindo a aparecer se, além de possuí-las, a mulher também for bela. As belas mulheres têm o direito de ser sábias e justas, e só elas. $^{18}$

Enfim, o curto parágrafo do Tratado termina com a inversão completa da hipótese por meio da qual ele é aberto, hipótese de que seria por natureza que as mulheres são frágeis e estão sob o poder dos homens, muito pelo contrário, as linhas finais do parágrafo nos mostram como sua submissão é dada por instituição (ou seja, dada de maneira histórica e cultural) a partir da relação de poder com os homens que socialmente as "educam" de modo

${ }^{16}$ CHAUI, “Terceira margem. Notas para um rodapé selvagem”, p. 57-58.

${ }^{17}$ ESPINOSA, Tratado político, p. 140.

${ }^{18}$ CHAUI, “Terceira margem. Notas para um rodapé selvagem”, p. 57. 
a terem menos poder: "Manipulada e dependente, a mulher é produzida como um ser ressentido, porque não é reconhecida; e a tirania é um efeito de sua dependência e não a definição de seu ser"'19.

Chaui explicita as inversões no argumento do Tratado político: "o que é interessante notar é que ao falar na fragilidade feminina Espinosa mencione as Amazonas, e que ao falar na tirania feminina, coloque-a na dependência do olhar masculino" ${ }^{20}$. É notável como, quando lido adequadamente, Espinosa em 1677 nega a ideia da submissão das mulheres por meio de uma natureza biológica (o termo biológico é ressaltado por Chaui), muito pelo contrário, ele nos mostra como a submissão é produzida na relação histórica com os homens.

Voltemos para as Amazonas. Tendo em mente que a política na Grécia se realiza em praças e assembleias masculinas, nelas as mulheres e os escravos não participam justamente porque pertencem a uma outra esfera, a da família. Na Grécia antiga, a família é a casa, o chefe da família (em grego: despotês) é dotado de poder de vida e morte sobre os membros da casa, dotado de poder de vida e morte sobre suas mulheres, filhos e escravos. A restrição das mulheres à esfera da família traz o infortúnio precisamente formulado por Hannah Arendt em $A$ condição bumana de que o espaço privado da família não é apenas o da privacidade, mas é sobretudo o da privação, estar privado de cidadania real e no caso das mulheres gregas também a privação do direito de vida e morte. Dadas as familiares circunstâncias desumanas em que a mulher grega se encontrava, torna-se evidente a conclusão de Chaui: "Nada surpreendente se, ao tomarem o poder, as Amazonas suprimam o outro que já as suprimiu como humanas" 21 .

Para, enfim, se contrapor à exclusão das mulheres em uma democracia adequadamente concebida de forma espinosana, Chaui irá produzir uma última inversão, para tanto, ela remete às duas teses centrais do Tratado político:

Com efeito, a primeira tese do Tratado é a de que os homens costumam ignorar a quem cabe efetivamente a soberania e confundem aquele que ocupa o poder com o próprio poder; a segunda tese do Tratado é a de que o inimigo do corpo político é sempre interno e está encarnado nos particulares (indivíduos ou classes) que querem assenhorar-se da soberania coletiva. ${ }^{22}$

O conciso texto de Chaui apenas cita as duas teses sem detalhar seu desenvolvimento, mas podemos logicamente inferir que a divisão e hierarquização entre homens e mulheres faz com que os homens ignorem a quem efetivamente cabe a soberania em uma democracia, ou seja, eles ignoram a soberania da coletividade, pois vêm confundir a sua posição no governo com o próprio poder de governar. Deste modo, eles se tornam o inimigo interno da própria democracia, pois encarnam uma particularidade na divisão social que visa se assenhorar da soberania coletiva, levando à exclusão das mulheres, ou seja, de praticamente metade dessa sociedade nas decisões políticas. Assim, a divisão e hierarquização de gêneros que engendra a soberania masculina produz exemplos claros daquilo que o Tratado propõe

\footnotetext{
${ }^{19}$ CHAUI, "Terceira margem. Notas para um rodapé selvagem”, p. 57.

${ }^{20}$ CHAUI, "Terceira margem. Notas para um rodapé selvagem", p. 57.

${ }^{21}$ CHAUI, "Terceira margem. Notas para um rodapé selvagem", p. 57.

${ }^{22}$ CHAUI, "Terceira margem. Notas para um rodapé selvagem”, p. 58.
} 
serem os dois principais impedimentos à vida política. A particularização da soberania masculina não sustenta a democracia, mas impede a sua efetiva realização.

A última inversão proposta torna a participação feminina necessária para que a democracia não prepare a sua própria ruína. Chaui volta-se mais uma vez para a estratégia da inversão estilística, mostrando como ela fundamenta, nos capítulos do Tratado relativos à monarquia e à aristocracia, o cerne da ideia espinosana de que a "arte de governar" é um permanente rearranjo das relações de poder para que a soberania não seja assenhorada por nenhum particular.

Retomemos o caso da monarquia cuja inversão havíamos apresentado a partir da perspectiva estilística. Lembremos da "estranha" tese espinosana que afirma a manutenção da monarquia pela criação de um exército popular permanente, armando o povo, Espinosa lhe dá o manejo das armas que só o rei possuía e que era a fonte de sua dominação. Uma tese já não mais tão estranha que é somada por mais duas ideias que também comportam inversões na lógica que originalmente institui o poder monárquico: as ideias de propriedade coletiva do solo e de uma assembleia soberana; três ações políticas que definitivamente esvaziam a identidade entre governante e poder soberano, impedindo que o monarca cause a ruína do reino.

Para não nos alongarmos mais, apenas citemos a concisa passagem de Chaui em relação à aristocracia: "Na aristocracia, uma rede complexa de aparelhos estatais deve fazer com que o poder seja exercido pelos melhores e não pelos maiores, de sorte que o poder deve ser realizado tendo em mira a luta de classes entre o patriciado e a plebe". ${ }^{23}$

Após nos movimentarmos por uma série de inversões - da fragilidade feminina à força das Amazonas; da tirania feminina à dependência desta ao olhar masculino; da naturalização da submissão das mulheres à sua forma historicamente instituída; das causas instituintes da monarquia e aristocracia às suas paradoxais anulações, da democracia masculina ao próprio homem como sua interna ruína - a conclusão do feminismo espinosano no ensaio de Marilena Chaui torna-se algo não apenas possível, mas rigorosamente necessário:

que o político deve criar o sujeito político, e "arranjar as coisas" significa criar condições para uma vida política onde a soberania coletiva não se destrua nas mãos dos particulares. Ora, se é o político que cria o sujeito político, e se a democracia cria e conserva homens livres, não porque seu desejo imediato seja a liberdade, mas porque a vida coletiva produz e reproduz a necessidade da liberdade, por que, então, não imaginar que, assim como rei foi neutralizado e os maiores, substituídos pelos melhores, em virtude da lógica interna do político, por que não imaginar, repito, que a democracia pudesse criar uma independência e liberdade femininas como efeito da própria vida política? O texto de Espinosa não formula esta hipótese, mas não deixa de abrir o campo onde ela se torna possível. ${ }^{24}$

${ }^{23}$ CHAUI, "Terceira margem. Notas para um rodapé selvagem", p. 58.

${ }^{24}$ CHAUI, "Terceira margem. Notas para um rodapé selvagem", p. 58. 
Engenhosa, a última frase de Chaui ainda poderia ser causa de certa perplexidade se nós não nos lembrássemos da primeira inversão proposta pela filósofa: a de que as hipóteses levantadas por Espinosa devem ser internamente destruídas em um movimento que necessariamente afirma o seu contrário. Enfim, podemos compreender porque Bento de Espinosa para ser um feminista, avant la lettre, em seu inacabado Tratado político não apresenta a hipótese da participação das mulheres na democracia, pois para torná-la uma necessidade, era preciso formular a hipótese contrária.

\section{Apêndice - Por um mapeamento do Feminismo Espinosano}

"I think this might be a terrible thought for her, but I would ask that she consider that the Spinozan conatus remains at the core of my own work."

Undoing Gender, Judith Butler

Dado o ainda diminuto número de pesquisas acerca do feminismo espinosano no meio brasileiro, resolvemos elaborar uma listagem das principais autoras, textos, livros e pesquisas que fazem parte deste debate, sobretudo, internacional, pois cremos que um primeiro mapeamento possa contribuir para futuras pesquisas sobre o assunto em nosso meio. Cabe ressaltar que embora a listagem seja extensa e realizada com empenho, ela permanece definitivamente incompleta, incitando, sempre, o convite a mais e novos nomes.

Esquematicamente há três formas de trabalho que visam unir feminismo com o pensamento de Espinosa e vêm constituir o multifacetado debate do feminismo espinosano: I - feministas que recorrem a Espinosa; II - especialistas espinosanas que pontualmente trabalham com questões de gênero na obra de Espinosa; e, por fim, III - feministas espinosanas. Cabe, também, salientar que parte das autoras poderia ser situada em mais de uma das três categorias.

Como todas as autoras (e alguns pontuais autores) mencionadas são feministas, operam no campo da filosofia e trabalham com a obra de Espinosa, evitaremos repetir excessivamente os termos filósofa, feminista, Espinosa, espinosista na listagem abaixo, embora tais termos sempre estejam implícitos na lista. Além disto, como são autoras com um vasto número de artigos e livros, apenas mencionaremos algumas de suas publicações que mais claramente trabalham com suas propostas de feminismo espinosano.

\section{I - Feministas que recorrem a Espinosa}

São autoras cujas trajetórias intelectuais são dedicadas ao feminismo, questões de gênero e sexualidade e que recorrem à obra de Espinosa (algumas vezes indiretamente por meio de algum filósofo espinosano) para fundamentar suas ideias. (Curiosamente, algo que valeria ser interpretado em relação a tais autoras é a forte presença de uma atuação interdisciplinar com o universo artístico, sendo autoras que comumente também realizam instalações, performances artísticas e criações literárias.)

a) Comecemos com o exemplo da italiana Chiara Bottici que dirige a área de estudos de gênero na New School for Social Research de Nova Iorque, sua pesquisa é dedicada à 
fundamentação do anarcofeminismo, tendo encontrado na ideia de transindividualidade espinosista (elaborada por Étienne Balibar) um caminho para fundamentar uma proposta capaz de suplantar os limites do feminismo interseccional que, embora seja elogiado pela autora, ainda estaria aquém da forma mais complexa e rica do anarcofeminismo. Ver "Bodies in plural: Towards an anarcha-feminist manifesto" (2018).

b) Como Gilles Deleuze foi responsável por uma grande revalorização da filosofia de Espinosa a partir da segunda metade do século XX, praticamente transformando-se em uma linhagem própria de espinosismo, muitas das feministas que recorrem a Espinosa o fazem por meio deste autor; dentre elas, destaca-se a renomada herdeira do pensamento deleuziano, Rosi Braidotti, autora ítalo-australiana cujas propostas pós-humanistas, ecofeministas e tecnológicas também a aproximam do pensamento de Donna Haraway. Desde 1988 Braidotti leciona na cadeira de estudos das mulheres na Universidade de Utrecht na Holanda (um dos principais centros de estudo da obra de Espinosa), onde em 1995 tornou-se a diretora fundadora do Netherlands research school of Women's Studies. Seu feminismo espinosano pode ser encontrado em Nomadic theory (2011).

c) Também recorrendo fortemente a Deleuze, temos $\mathrm{x}$ artistx, escritorx, poeta, filósofx e perfomer pós-porno argentinx Leonor Silvestri, cujos livros em destaque são Zine Spinoza - Taller mecánico para máquinas sensibles (2016) e Primavera Con Monique Wittig. El Devenir Lesbiano Con El Dildo En La Mano De Spinoza Transfeminista (2019).

d) Trabalhando na conjunção entre biopolítica, lesbianismo, animalismo e problemas ecológicos, temos Isabel Balza, Professora Titular de Filosofia Moral na Universidad de Jaén na Espanha. Texto em destaque "Los feminismos de Spinoza: corporalidad y renaturalización" (2014).

e) Ainda que possuindo uma obra polimórfica, Judith Butler em Undoing Gender (2004) vem explicitamente "considerar o conatus espinosano como um dos elementos presentes no cerne de seu próprio trabalho" 25 . Neste livro, elx marca a relevância do filósofo sobretudo em seu fecundo diálogo com Rosi Braidotti (posição b da lista) e, também, na apresentação do relato autobiográfico de que, ainda muito jovem, a Ética de Espinosa veio a ser a sua primeira leitura de filosofia, impactando-x muito antes de iniciar sua trajetória na área de filosofia, trajetória que segundo x autorx permanece sob o impacto da obra do filósofo. O quinto capítulo de seu livro Senses of the subject (2015) é o ensaio "Spinoza's Ethics under Pressure" inteiramente voltado à interpretação da filosofia espinosana.

Algumas pesquisadoras vêm trabalhando a presença de Espinosa na obra butleriana, colocando em relevo uma ligação ainda maior entre os dois autores, ver: Desire for Recognition? Butler, Hegel, and Spinoza (2011) de Hasana Sharp (posição r na lista); Of Suicide and Falling Stones: Finitude, Contingency, and Corporeal Vulnerability in (Judith Butler's) Spinoza (2012) de Gordon Hull e "Um corpo para Judith Butler" (2015) da brasileira Patrícia Porchat.

Dentre o grande número de autoras feministas que recorrem a Espinosa, destacamse também:

f) Maite Larrauri de "Spinoza y las mujeres" (1989, traduzido em 2006 em "Spinoza e as mulheres", Kalagatos, Fortaleza, v. 3, n. 6).

${ }^{25}$ BUTLER, Undoing Gender, p. 198. 
g) Beth Lord de “"Disempowered by Nature': Spinoza on The Political Capabilities of Women" (2011) e "The Impersonal is Political: Spinoza and a Feminist Politics of Imperceptibility" (2009).

h) Susan James de Freedom and the Imaginary (2002).

i) Por fim, tomamos a liberdade de adicionar um texto de nossa autoria, um dos poucos encontrados na produção brasileira: "Clarice e Espinosa: batidas (des)ordenadas entre dois corações” (2018). O ensaio, escrito a quatro mãos com Luís César Oliva, Professor da Universidade de São Paulo, procura mostrar como o romance Perto do coração selvagem (1943) de Clarice Lispector, ao tratar de temas que vão de Deus à sexualidade das mulheres, porta a interpretação pessoal de Lispector de conceitos centrais de Espinosa e como tais conceitos possuem função estrutural na trama do romance.

\section{II - Espinosanas que trabalham questões de gênero na obra de Espinosa}

Neste caso enquadram-se as especialistas e filósofas que dedicam suas trajetórias ao estudo e à reflexão acerca da obra de Espinosa, são autoras cujas biografias concernem, sobretudo, à obra de Espinosa e que acabam por abordar a questão das mulheres e da sexualidade na obra do filósofo.

j) O artigo "Terceira margem. Notas para um rodapé selvagem” (1976) de Marilena Chaui, Professora Emérita da Universidade de São Paulo, pode ser tomado como a obra precursora do que amplamente denominamos de feminismo espinosano, antecedendo tanto o célebre texto Part of Nature: Self-Knowledge in Spinoza's Ethics (1994) de Genevieve Mary Lloyd (posição o na lista) por dezoito anos, como, também, o "Spinoza y las mujeres" (1989) de Maite Larrauri (posição f na lista) por treze anos.

Ao ter contato com o presente artigo, Chaui nos encaminhou um segundo texto de sua autoria: "Sobre as Mulheres: notas para um rodapé selvagem" de 2002. Um texto mais longo que, embora motivado pelo mesmo problema da exclusão da participação das mulheres na democracia no Tratado politico, trabalha com argumentos diferentes dos empregados em 1976, analisando dentre outras: a condição histórica das mulheres na Holanda seiscentista; a igualdade de gênero por meio da ontologia da Ética de Espinosa; a necessária ressignificação do papel da experiência no interior do Tratado, mostrando que a exclusão histórica da participação das mulheres é afirmada por uma experiência que, enquanto experiência, negará a si mesma; uma análise mais detida da lógica de como o olhar masculino produz a servidão das mulheres. Contudo, como o artigo já havia sido aprovado para publicação nos Cadernos de Ética e Filosofia Política, sendo nosso escopo, sobretudo, uma interpretação do ensaio de 1976, julgamos ser melhor abordar as questões provenientes do novo texto de Chaui em um artigo futuro. Por fim, gostaríamos de salientar que este segundo texto de Chaui, ainda não publicado, serviu de base para uma palestra pronunciada no lançamento do sétimo número da revista Cadernos Espinosanos que trouxe textos assinados exclusivamente por pesquisadoras da filosofia do século XVII, palestra que, na ocasião, foi proferida, também, em razão do Dia Internacional da Mulher em 2002.

Uma vez que a presente lista é um apêndice do artigo "O feminismo espinosano de Marilena Chaui”, convidamos à leitura do mesmo para maiores informações sobre a questão na obra da autora. 
k) Nesta categoria o caso mais singular vem a ser a filósofa portuguesa e Professora Catedrática da Faculdade de Letras da Universidade de Lisboa Maria Luísa Ribeiro Ferreira, ela tanto é uma reconhecida especialista na obra de Espinosa como, também, uma especialista em estudos de gênero, tendo publicado amplamente sobre ambos os temas, porém tais publicações não cruzam seus conteúdos, pois embora ela seja uma feminista e uma espinosana, ela não recorre à obra de Espinosa para fundamentar seu feminismo, muito pelo contrário, as menções ao filósofo em seus textos dedicados a gênero são muito pouco lisonjeiras. Contudo em seus dois textos dedicados especificamente à condição das mulheres na obra do filósofo, tanto em Haverá uma salvação para as mulheres? A hipótese do livro $V$ da Ética de Espinosa (2003), como em "Corpo potência e política - Espinosa e os direitos das mulheres" (2018), ela defende ideias como:

A interpretação que apresentamos [de Espinosa] não anula totalmente a estranheza, a perplexidade e mesmo o desagrado que o texto do Tratado político pode causar a uma leitora. Mas admite que os passos citados da Ética permitem uma ténue esperança - a de que, para Espinosa, as mulheres podem participar de pleno direito na salvação, sem que para tal tenham que renunciar ao seu corpo. ${ }^{26}$

1) A proposta do XIII Colóquio Internacional Spinoza, realizado em $2016 \mathrm{em}$ Córdoba, Argentina, foi um convite à interpretação de dez passagens "malditas", ou seja, consideradas antiespinosistas na obra de Espinosa, uma delas vindo a ser a situação das mulheres na conclusão do Tratado político. Das cinco apresentações que abordaram tal passagem e posteriormente foram publicadas em Spinoza Maledictus (JABASE et al., 2018), gostaríamos de salientar o precioso Gobernar a las mijeres. La proposición XI, 4 del Tratado Político de Spinoza, o los problemas de la relación naturaleza e historia de Cecilia Abdo Ferez, Professora da Universidad de Buenos Aires, que a partir da desconstrução espinosana do binarismo natureza e história, demonstra cuidadosamente como a trama argumentativa do tratado, na verdade, realiza uma crítica das supostas "naturais" debilidade e servidão das mulheres que as impediria de possuir um papel ativo na democracia. Ainda que por caminhos distintos, este é o texto que mais se aproxima às conclusões do "Terceira margem. Notas para um rodapé selvagem" de Marilena Chaui. Ver também Contra las mujeres. (In)Justicia en Spinoza (2019).

m) Aurelia Armstrong, Professora da The University of Queensland na Austrália, desenvolve trabalhos sobre autonomia relacional tendo em foco a obra de Espinosa, autora de "Autonomy and the relational individual: Spinoza and feminism" em Feminist interpretations of Benedict Spinoza (2009) organizado por Moira Gatens (posição p da lista). É, também, responsável pela coorganização com Keith Green e Andrea Sangiacomo de Spinoza and Relational Autonomy (2019) onde mais estudos sobre o encontro entre feminismo, espinosismo e autonomia relacional podem ser vislumbrados.

n) Emanuel Angelo da Rocha Fragoso, Professor da Universidade Estadual do Ceará e tradutor da edição brasileira de Spinoz̧a e as mulheres de Maite Larrauri (posição f da lista), é

${ }^{26}$ FERREIRA, “Corpo potência e política - Espinosa e os direitos das mulheres”, p. 269. 
autor de uma das poucas publicações brasileiras: $A$ condição politica da mulher no Tratado político de Benedictus de Spinoza (2017).

\section{III - Feministas espinosanas}

São autoras cujas trajetórias simultaneamente trazem uma grande contribuição de textos tanto sobre gênero, como sobre a obra de Espinosa e, mais que isso, são autoras que tem a obra de Espinosa como questão central para suas reflexões sobre feminismo.

o) Há uma forte linhagem australiana que começa com Genevieve Mary Lloyd, Professora Emérita na University of New South Wales, autora do clássico The Man of Reason (1984), dez anos após a publicação deste livro, ela lança sua primeira obra sobre feminismo espinosano, Part of Nature: Self-Knowledge in Spinoza's Ethics (1994). Esta última obra irá fundamentar uma linhagem de pensadoras que trabalham nesta mesma direção, a mencionada filosofa pós-humanista, ítalo-australiana, Rosi Braidotti (posição b na lista) foi aluna e discípula de Lloyd.

p) A australiana Moira Gatens, Professora na University of Sydney, também ex-aluna de Lloyd, é a autora mais citada e a maior impulsionadora do debate sobre feminismo espinosano, tendo se tornado uma interlocutora constante das diversas linhas de pensamento feminista, seu primeiro livro a tratar da conjunção entre Espinosa e feminismo foi Imaginary Bodies: Ethics, Power and Corporeality (1996). Em 1999, Lloyd e Gatens lançam a quatro mãos o livro que se tornará uma espécie de bíblia do feminismo espinosano, Collective imaginings: Spinoza, past and present. Em 2009 ela organiza a primeira antologia do assunto, a Feminist Interpretations of Benedict Spinoza (2009) contando com onze ensaios, destacando-se a colaboração de renomadas feministas como Luce Irigaray e de renomados espinosistas como Alexandre Matheron.

q) Também localizada na Austrália, Janice Richardson atualmente leciona na Monash University, Melbourne, trabalhando, sobretudo, com filosofia do direito e gênero em uma perspectiva espinosana, seu livro The Classic Social Contractarians: Critical Perspectives from Contemporary Feminist Philosophy and Law (2013) em perspectiva feminista contrapõem a tradicional história do contrato social à concepção espinosana para pensar formas diferentes de política e de relações intersubjetivas. No campo da filosofia do direito se destacam "Spinoza, Feminism and Privacy: Exploring an Immanent Ethics of Privacy" (2014) e "Spinoza's Conception of Personal and Political Change: A Feminist Perspective" (2020); no campo da estética "Spinoza, Kant and the sublime" (2019).

r) Por fim, a canadense Hasana Sharp, Professora na McGill University, autora de uma vasta produção sobre Espinosa, gênero e raça, suas principais publicações em que tais assuntos se cruzam são: Spinoza and The Politics of Renaturalization (2011); "Eve's Perfection: Spinoza on Sexual (In)Equality" (2012); e a coletânea de forte inspiração espinosana Feminist Philosophies of Life (2016). 


\section{Referências bibliográficas}

ARENDT, Hannah. A condição bumana. Rio de Janeiro: Forense Universitária, 2016.

ARMSTRONG, Aurelia. Autonomy and the relational individual: Spinoza and feminism. In: GATENS, Moira (org.). Feminist interpretations of Benedict Spinoza. State College: Pennsylvania State University Press, 2009.

ARMSTRONG, Aurelia; GREEN, Keith; SANGIACOMO, Andrea. Spinoza and Relational Autonomy. Edinburgh: Edinburgh University Press, 2019.

BALZA, Isabel. "Los feminismos de Spinoza: corporalidad y renaturalización”. Daimon, n. 63. Múrcia: 2014.

BOTTICI, Chiara. "Bodies in plural: Towards an anarcha-feminist manifesto". La Deleuriana, n. 8,2018 .

BRAIDOTTI, Rosi. Nomadic theory. Columbia: Columbia University Press, 2011.

BUTLER, Judith. Problemas de gênero. Rio de Janeiro: Civilização Brasileira, 2003. Undoing Gender. Abingdon: Routledge, 2004.

Spinoza's Ethics under Pressure. In: Senses of the subject. Nova Iorque: Fordham University Press, 2015.

CHAUI, Marilena. “Terceira margem. Notas para um rodapé selvagem”. Almanaque. Cadernos de Literatura e Ensaio, no 2, pp. 54-58. São Paulo: 1976.

Repressão sexual: essa nossa (des)conhecida. São Paulo: Brasiliense, 1984.

2002. "Sobre as Mulheres: notas para um rodapé selvagem", mimeo cedido pela autora.

No prelo, título a definir (volume sobre gênero e sexualidade) - Vol. 8 da Coleção Escritos de Marilena Chaui. Belo Horizonte: Editora Autêntica, 2021.

ESPINOSA, Bento. Tratado político. São Paulo: Editora Martins Fontes, 2009.

FEREZ, Cecilia Abdo. Gobernar a las mujeres. La proposición XI, 4 del Tratado Político de Spinoza, o los problemas de la relación naturaleza e historia. In: JABASE, A. L.; MERILES, A.; PRONELlO, C. L.; RIVERA, F. (org). Spinoza Maledictus. Córdoba: Universidad Nacional de Córdoba, 2018.

FEREZ, Cecilia Abdo. Contra las mujeres. (In)Justicia en Spinoza. Madri: Ediciones Antígona, 2019. 
FERREIRA, Maria Luísa Ribeiro. Haverá uma salvação para as mulheres? A hipótese do livro V da Ética de Espinosa. In: Uma suprema alegria: escritos sobre Espinosa. Coimbra: Quarteto, 2003.

"Corpo potência e política - Espinosa e os direitos das mulheres". In: Araucária, Rev. Iberoamericana de Filosofia, Politica y Humanidades, n. 39. Sevilha: 2018.

FRAGOSO, Emanuel Angelo da Rocha. A condição política da mulher no Tratado político de Benedictus de Spinoza. In: BECKER, C.; FRAGOSO, E.; GUIMARAENS, F.; ITOKAZU, E.; ROCHA, M.. Spinoza e nós. Vol. 2. Rio de Janeiro: Ed. PUC-Rio, 2017.

GATENS, Moira. Imaginary Bodies: Ethics, Power and Corporeality. Routledge, Abingdon, 1995. Feminist Interpretations of Benedict Spinoza. State College: Pennsylvania State University Press, 2009.

GATENS, Moira; LLOYD, Genevieve Mary. Collective imaginings: Spinoza, past and present. Abingdon: Routledge, 1999.

HULL, Gordon. Of Suicide and Falling Stones: Finitude, Contingency, and Corporeal Vulnerability in (Judith Butler's) Spinoza. In: SHARP, Hasana; SMITH, Jason E. (eds). Between Hegel and Spinoza: A Volume of Critical Essays. Londres: Bloomsbury, 2012, pp. 151 169.

JABASE, Ana Leila; MERILES, Alejandra; PRONELLO, Carmela Las heras; RIVERA, Francisco (orgs.). Spinoza Maledictus. Córdoba: Universidad Nacional de Córdoba, 2018.

JAMES, Susan. Freedom and the Imaginary. In: JAMES, Susan; PALMER, Stephanie (eds.). Visible Women: Essays on Feminist Legal Theory and Political Pbilosophy. Londres: HartBloomsbury, 2002.

LARRAURI, Maite. "Spinoza y las mujeres". Documento de trabajo do Department of Spanish \& Portuguese, University of Minnesota, n. 9 (traduzido como "Spinoza e as mulheres", 2006, em Kalagatos, v. 3, n. 6, Fortaleza). Minneapolis: 1989.

LISPECTOR, Clarice. Perto do coração selvagem. Rio de Janeiro: Rocco, 1943.

LLOYD, Genevieve Mary. The Man of Reason. Londres: Methuen, 1984.

. Part of Nature: Self-Knowledge in Spinoza's Ethics. Ithaca: Cornell University Press, 1994.

LORD, Beth. "The Impersonal is Political: Spinoza and a Feminist Politics of Imperceptibility". Hypatia, vol. 24, n. 4, 2009.

“"Disempowered by Nature': Spinoza on The Political Capabilities of Women". British Journal for the History of Philosophy, vol. 19, n. 6, 2011. 
MATHERON, Alexandre. Femmes et serviteurs dans la démocratie spinoziste. In: HESSING, Siegfreid (ed.). Speculum Spinozanum 1677-1977. Abingdon: Routledge and Kegan Paul, pp. 368-386, 1978.

OLIVA, Luís César; XAVIER, Henrique. "Clarice e Espinosa: batidas (des)ordenadas entre dois corações”. Santa Barbara Portuguese Studies, v. 2. Santa Barbara: 2018.

PORCHAT, Patrícia. “Um corpo para Judith Butler”. Periodicus, n. 3, v. 1. Salvador: 2015.

RICHARDSON, Janice. The Classic Social Contractarians: Critical Perspectives from Contemporary Feminist Philosopby and Law. Routledge, Abingdon: 2013.

. "Spinoza, Feminism and Privacy: Exploring an Immanent Ethics of Privacy". Fem Leg Stud, n. 22, 2014.

2019.

"Spinoza, Kant and the sublime". Textual Practice, Volume 33, Issue 5: Spinoza's Artes,

. "Spinoza's Conception of Personal and Political Change: A Feminist Perspective".

Law and Critique, vol. 31, 2020.

SHARP, Hasana. Desire for Recognition? Butler, Hegel, and Spinoza. In: Spinoza and the Politics of Renaturalization. Chicago: University of Chicago Press, 2011.

Spinoza and The Politics of Renaturalization. Chicago: University of Chicago Press, 2011.

"Eve's Perfection: Spinoza on Sexual (In)Equality". Journal of the History of Philosophy, n. 50.4. Baltimore: 2012.

SHARP, Hasana; TAYLOR, C. (org). Feminist Philosophies of Life. Montreal: McGill-Queen's University Press, 2016.

SILVESTRI, Leonor. Zine Spinoz̧a - Taller mecánico para máquinas sensibles. Zine virtual, publicado pela autora, 2016.

Primavera Con Monique Wittig. El Devenir Lesbiano Con El Dildo En La Mano De Spinoza Transfeminista. Buenos Aires: Queen Ludd, 2019.

XAVIER, Henrique. "Histórias da sexualidade à brasileira". In: BREGANTINI, Daysi (org.). Marilena Chawi: pensamento, afetos e análise da obra. São Paulo: Editora Cult, 2020. 